\title{
Seismic quiescence precursors to two M7 earthquakes on Sakhalin Island, measured by two methods
}

\author{
Max Wyss ${ }^{1}$, Gennady Sobolev ${ }^{2}$, and James D. Clippard ${ }^{3}$ \\ ${ }^{1}$ World Agency of Planetary Monitoring and Earthquake Risk Reduction, Geneva \\ ${ }^{2}$ Russian Academy of Sciences, Moscow, Russia \\ ${ }^{3}$ Shell International Exploration and Production B.V., Rijswijk
}

(Received September 11, 2003; Revised March 11, 2004; Accepted March 15, 2004)

Two large earthquakes occurred during the last decade on Sakhalin Island, the $M_{w} 7.6$ Neftegorskoe earthquake of 27 May 1995 and the $M_{w} 6.8$ Uglegorskoe earthquake of 4 August 2000, in the north and south of the island, respectively. Only about five seismograph stations record earthquakes along the $1000 \mathrm{~km}$, mostly strike-slip plate boundary that transects the island from north to south. In spite of that, it was possible to investigate seismicity patterns of the last two to three decades quantitatively. We found that in, and surrounding, their source volumes, both of these main shocks were preceded by periods of pronounced seismic quiescence, which lasted $2.5 \pm 0.5$ years. The distances to which the production of earthquakes was reduced reached several hundred kilometers. The probability that these periods of anomalously low seismicity occurred by chance is estimated to be about $1 \%$ to $2 \%$. These conclusions were reached independently by the application of two methods, which are based on different approaches. The RTL-algorithm measures the level of seismic activity in moving time windows by counting the number of earthquakes, weighted by their size, and inversely weighted by their distance, in time and space from the point of observation. The $Z$-mapping approach measures the difference of the seismicity rate, within moving time windows, to the background rate by the standard deviate $Z$. This generates an array of comparisons that cover all of the available time and space, and that can be searched for all anomalous departures from the normal seismicity rate. The RTL-analysis was based on the original catalog with $K$-classes measuring the earthquake sizes; the $Z$-mapping was based on the catalog with $K$ transformed into magnitudes. The RTL-analysis started with data from 1980, the $Z$-mapping technique used the data from 1974 on. In both methods, cylindrical volumes, centered at the respective epicenters, were sampled. The Z-mapping technique additionally investigated the seismicity in about 1000 volumes centered at the nodes of a randomly placed regular grid with node spacing of $20 \mathrm{~km}$. The fact that the two methods yield almost identical results strongly suggests that the observed precursory quiescence anomalies are robust and real. If the seismicity on Sakhalin Island is monitored at a completeness-level an order of magnitude below the present one, then it may be possible to detect future episodes of quiescence in real time.

Key words: Earthquake prediction, seismic quiescence, seismicity patterns.

\section{Introduction}

Precursory seismic quiescence is the inner part of the doughnut pattern proposed by Mogi (1969) on the basis of visual inspection of seismicity maps. Wyss and Habermann (1988b) defined the phenomenon formally. Their amended definition reads as follows. "Seismic quiescence is a decrease of mean seismicity rate as compared to the background rate in the same crustal volume, judged significant by some clearly defined standard. The rate decrease takes place within part, or all, of the source volume of the subsequent main shock, and it extends up to the time of the main shock, or may be separated from it by a relatively short period of increased seismicity rate. Usually, the rate decrease is larger than $40 \%$, and takes place in all magnitude bands." The proposal of precursory quiescence to aftershocks by Matsu'ura (1986) was accepted by the IASPEI sub-commission on earthquake prediction as a precursor phenomenon (Wyss,

Copy right(c) The Society of Geomagnetism and Earth, Planetary and Space Sciences (SGEPSS); The Seismological Society of Japan; The Volcanological Society of Japan; The Geodetic Society of Japan; The Japanese Society for Planetary Sciences; TERRAPUB.
1991). However, the proposal of Wyss (1997a) of quiescence before main shocks as a precursor was placed in the "undecided" category by the experts working on behalf of that same sub-commission (Wyss, 1997b). Thus, the hypothesis of precursory seismic quiescence is not universally accepted, although at least 80 authors have published case histories of this phenomenon.

Case histories are not a sufficiently rigorous approach to test a hypothesis. However, lacking the resources to conduct a global survey of the seismicity patterns before all large earthquakes in all catalogs, or to attempt real time identification of the phenomenon by monitoring seismicity, case histories are the only way to learn more about precursory seismic quiescence. Case histories have value if quantitative and rigorous methods are used, which measure the amount of the rate decrease, the statistical significance of this change, the spatial extent of the anomaly, and, if possible, estimate the probability that it occurred by chance.

If several main shocks have occurred within an area covered by a local or regional earthquake catalog, one can test the hypothesis for all of these events (Arabasz and Wyss, 


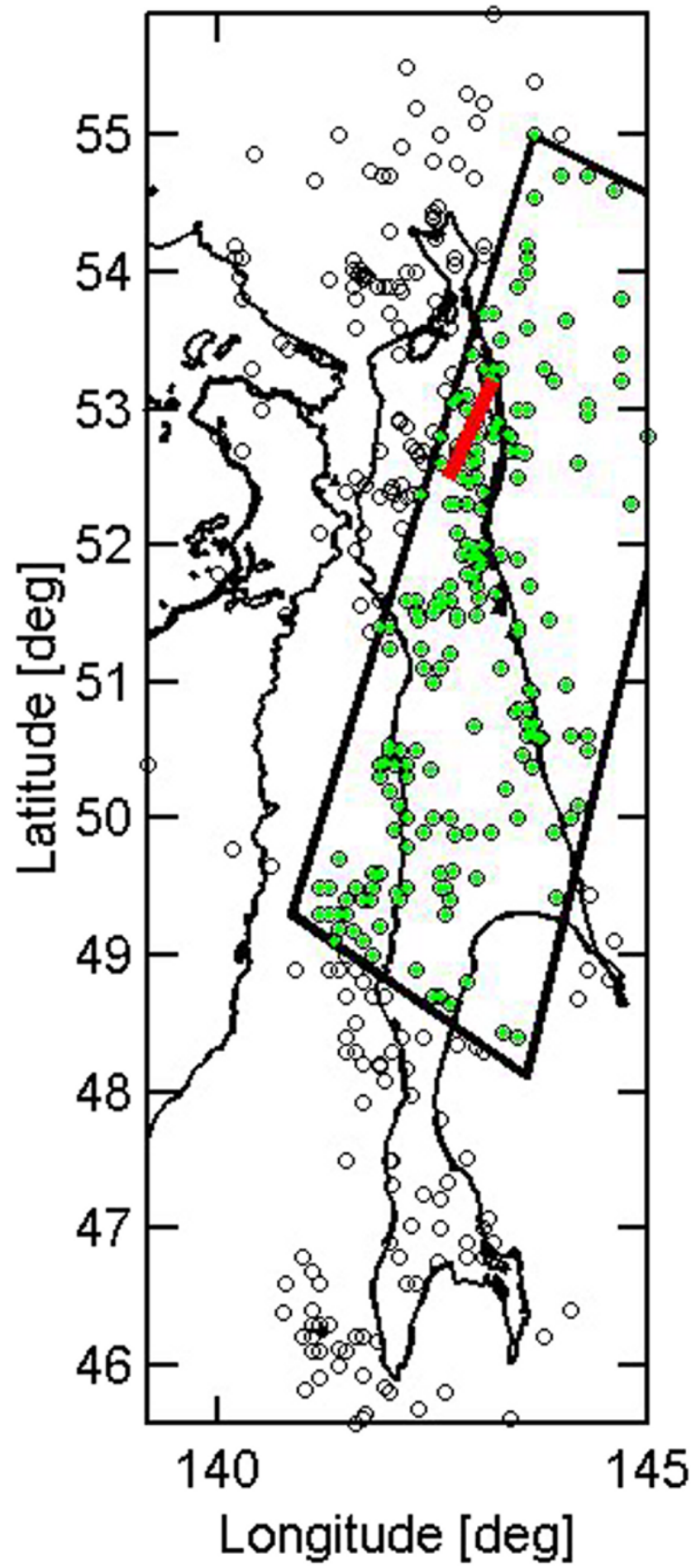

Fig. 1. Epicenter map of Sakhalin Island for 1974-1995.4 and $M \geq 3.4$. The solid straight line marks the 1995 aftershock zone. The rectangle shows one of the definitions of the area of precursory quiescence.

1996b). However, often, there is only one large event available for analysis (e.g. Wyss et al., 1997; Wyss and Martyrosian, 1998). On Sakhalin Island, two main shocks of M7 class occurred during the period for which modern seismicity data are available; the $M_{w} 7.6\left(M_{s} 7.6\right)$ Neftegorskoe earthquake of May 27, 1995, and the $M_{w} 6.8\left(M_{s} 7.1\right)$ Uglegorskoe earthquake of Aug. 4, 2000. Here, we examine the hypothesis that both of these large ruptures were preceded by seismic quiescence in and near their source volumes.

There exist different approaches to measure, map and evaluate possible episodes of seismic quiescence. This has the disadvantage that the results reported by different authors may not be easily compared, but it has the advantage that one may gain more confidence in a pattern that is detected by different methods. Also, the uncertainties in the results may be estimated by comparison and additional insights may be gained because of intrinsic differences in the statistical characterization of anomalies. In the following, we present the analysis of seismicity patterns in Sakhalin Island by two approaches.

\section{Data}

Earthquakes are produced at a relatively low rate all along Sakhalin Island, which extends approximately $1000 \mathrm{~km}$ from north to south (Fig. 1). Currently, there are about five seismograph stations monitoring this seismicity, with additional readings supplied from stations in Kamchatka and the Russian mainland. The catalog for Sakhalin Island, of the Russian Academy of Sciences (RAS), contains 2166 events with depths less than $80 \mathrm{~km}$ for the period 1974-2002. About $90 \%$ of the hypocenters in the catalog have depths $H<80$ $\mathrm{km}$. In this depth-interval, $92 \%$ are shallower than $20 \mathrm{~km}$.

In the RAS catalog, the size of the earthquakes is measured by the energy class $K$, from which the magnitude, $M_{L H}$, can be calculated by

$$
M_{L H}=(K-1.2) / 2
$$

for events with depth $H<80 \mathrm{~km}$ (Soloviev and Solovieva, 1967). The analysis using the RTL-algorithm was performed based on the $K$-classification. In the $Z$-value method, magnitudes were used. The approach of dealing with the heterogeneity of reporting, which is present in all catalogs, was also different in the two methods of analysis.

Aftershocks add noise to both methods of seismicity rate analysis used here. Therefore, we used declustered catalogs as the basic data sets. For the RTL-analysis, we eliminated aftershocks using the program written by Smirnov (1998) on the basis of the algorithm of Molchan and Dmitrieva (1991). In this approach, the principle of separating aftershocks from other events, which are called background, is based on the comparison of their functions and their distribution in time and space. Background events are assumed to be uniformly distributed in space and time. Aftershocks are assumed to be normally (Gaussian) distributed in space and temporally governed by the Omori law. For the $Z$-value analysis, the algorithm by Reasenberg (1985) was used for declustering. This method eliminates aftershocks, as well as clusters of events judged sufficiently close to each other in space and time to be considered interdependent. With this algorithm, only $10 \%$ of the events are judged to be clusters, excluding the aftershock sequence to the 1995 main shock. The $Z$-analysis was done with both the raw and declustered cata$\operatorname{logs}$, and the differences in results are insignificant.

The minimum magnitude of complete reporting $\left(M_{c}\right.$ and the corresponding $K_{c}$ ) is defined as the magnitude to which the Gutenberg-Richter frequency-magnitude power law is valid. Changes of this parameter with time are of concern to all investigations of seismicity rate. For this reason, we 
investigated the level and the stability of $K_{c}$ and $M_{c}$. For the data set using $K$ as measure of the earthquake size, it was found that $K_{c}=8$, using the algorithm developed by Smirnov (1998). This method is based on verification of the hypothesis that the observed size distribution agrees with the Gutenberg-Richter relation. For the $Z$-value study the same principle was used, but the catalog with $M$ as the measure of size was searched for changes of $M_{c}$ as a function of time, using the software package ZMAP (Wiemer, 2001). This analysis showed that $M_{c}$ was stable from 1974 on. For most years $M_{c}=3.4$, especially in the $1970 \mathrm{~s}$ and early $1980 \mathrm{~s}$. $M_{c}=3.4$ corresponds to $K_{c}=8$, according to (1).

The reporting rate in the catalog was approximately constant over long periods, but two instances of significant change can be seen in cumulative plots of earthquakes as a function of time. These occurred in 1980 and in 1988. We investigated them by the algorithm GENAS (Habermann, 1983) to determine if they showed features of artificial reporting rate changes, such as are observed due to inadvertent changes in magnitude scale. The magnitude signatures (Habermann, 1987) of both rate changes did not show features that could have been interpreted as magnitude shifts. We therefore accepted the catalog from 1974 on without changes in the $Z$-value analysis. For the analysis with the RTL-algorithm, a different decision was made. Although it was also found that the catalog was approximately complete at the $K_{c}=8$ level back to 1974 , the RTL-analysis was sensitive to the reporting change in 1980 . It turned out that before this time there were no $K$-values given between 8.5 and 9 , but afterwards all decimal $K$-values were present. Therefore, 1980 was selected as the starting date for data used in the RTL-analysis.

We consequently performed our analysis on several data sets. (1) The declustered catalog with $M \geq M_{c}$ for the period 1974-1995.4, $N=401$ events (Fig. 1). (2) All events reported in the catalog for the period 1974-1995.4, assuming that the percentage of incompletely recorded events remained the same through time. The number of events in this catalog were $N_{\text {all }}=529$. (3) The catalog with aftershocks removed and with $K \geq 8$ for the period 1980-1995.4, for which $N(K 8)=283$.

In the end, the results of the two methods, using somewhat different criteria to select the data, agree. This shows that the details of the data selection do not produce the observed anomalies.

\section{Sakhalin Tectonics and Main Shock Source Pa- rameters}

The seismic activity in Sakhalin Island is due to a still poorly understood plate boundary (Chapman and Solomon, 1976; Seno et al., 1996). A near-vertical strike-slip fault zone, striking essentially NS, passes through the entire island, separating the Asian plate from the Okhotsk plate (Zanyukov, 1971). The seismicity is low and large fault ruptures occur relatively infrequently.

On May 27, 1995, an $M_{w} 7.6$ earthquake devastated the city of Neftegorsk in northern Sakhalin (Arefiev et al., 2000). This was one of the worst earthquake disasters in Russian history because 2800 people perished in the city of Neftegorsk. The length of the aftershock area was about $60 \mathrm{~km}$, and the rupture length of the main shock, estimated from surface wave analysis, was 20-30 km (Katsumata et al., 2002). A surface rupture of $35 \mathrm{~km}$ length and $7 \mathrm{~m}$ maximum displacement was mapped (Shimamoto et al., 1996). The rupture occurred along the previously mapped Gyrgylan'i-Ossoi fault (Fournier et al., 1994). The extent of the aftershock zone according to Katsumata et al. (2002) is shown as a solid line in Fig. 1.

\section{Methods}

\subsection{The $Z$-value method}

In the $Z$-value method, we compare the mean seismicity rate during a limited period and in a given area to the overall average rate in that area. The intent is to detect possible periods of anomalously low seismicity just before main shocks near their epicenters, and to evaluate the statistical significance of such a quiescence compared with all other rate decreases that may have happened at random times and locations. To achieve this, we rely on the standard deviate, $Z$, to estimate the significance of the rate change,

$$
Z=\left(M_{1}-M_{2}\right) /\left(S_{1} / n_{1}+S_{2} / n_{2}\right)^{1 / 2}
$$

where $M$ is the mean rate, $S$ the variance and $n$ the number of events in the first and second period to be compared. The larger the $Z$-value, the more significant the observed difference. Large numbers of samples enhance, large variances in the samples diminish, the significance. This parametric statistical method is based on the assumption of normally distributed samples, but is approximately valid for other distributions when the sample size is large.

Samples for which the rate is to be compared with the background rate are selected as follows. At every node of a grid with spacing $20 \mathrm{~km}$ that covers the study area, the nearest $N$ events are selected $(N=100,150,200$ in different runs). In each sample of $N$ events, the rate inside a window of $T_{w}$ is compared to the rate in the rest of that sample $\left(T_{w}=\right.$ $1.5,2,2.5$ years). The window is placed at every possible position in time, from the beginning to the end, stepping by one month. A total of $256 \mathrm{Z}$-values are therefore calculated for the period 1974-1995.4 at each of the approximately 1000 nodes. The set of $Z$-values thus generated for each node is defined as the 'Ita-function' because the rate within the window is compared to the Long Term Average rate. It can be plotted as a function of time, at any given node, for visual assessment of statistical significance of a rate change.

Usually, we generate a $Z$-map from these results, defining the areas of exceptionally anomalous rates (e.g. Wiemer and Wyss, 1994), given the position of $T_{w}$ just before the main shock, and at any other time of interest. In the case of the Neftegorskoe earthquake, the density of earthquakes is so low that the samples overlap substantially. As a consequence, it makes no sense to plot a map. Nevertheless, the array of about $2.6 \cdot 10^{5} \mathrm{Z}$-values generated is useful to answer the question: Did at any time, and at any position in space an episode of quiescence occur, similar to the one we propose as precursor? If the answer is "no, not at similar significance," then we claim that the quiescence hypothesis is tenable.

Another common sense approach to define the volume of possible precursory quiescence, is to sample the source volume with a geometrically simple shape (circle or rectangle) 
and to compare the rate in the last $T_{w}$ with the previous background rate in this sample. If quiescence is seen in such a sample, then the size of the circle or rectangle is increased, until the significance of the quiescence, as measured by the $Z$-value, diminishes. This approach is based on the hypothesis that the quiescence is tied to the source volume and its surroundings.

To reduce subjectivity in the sampling to a minimum, we use simple geometrical shapes and window steps in 0.5 years, only. The position of the grid, which forms the center points of circular areas in which we search for anomalies that may exist in random locations and times, is chosen at random. The statistical significance of the observed maximal $Z$-value are finally estimated by generating large numbers of data sets with the same properties as the one at hand, and by computing a distribution of maximum $Z$-values for the random data sets.

\subsection{The RTL-algorithm}

The RTL-method uses three functions to measure the state of seismicity at a given location as a function of time. $R(x, y, z, t)$ assigns a decreasing weight to each earthquake in the catalog as a function of epicentral distance from the point of interest, $T(x, y, z, t)$ decreases the weight of each event as a function of the difference from the time of interest, and $L(x, y, z, t)$ weighs the contribution to the algorithm by the rupture length of each event (Huang et al., 2002, 2001; Sobolev, 2001; Sobolev and Tyupkin, 1997, 1999).

These functions are defined as

$$
\begin{aligned}
& R(x, y, z, t)=\left[\Sigma \exp \left(-r_{i} / r_{o}\right)\right]-R_{l t r} \\
& T(x, y, z, t)=\left[\Sigma \exp \left(-\left(t-t_{i}\right) / t_{o}\right)\right]-T_{l t r} \\
& L(x, y, z, t)=\left[\Sigma\left(l_{i} / r_{i}\right)^{p}\right]-L_{l t r} .
\end{aligned}
$$

In these formulas, $x, y, z$, and $t$ are the coordinates, the depth and the analysis time, respectively. $r_{i}$ is the epicentral distance from the location selected for analyses, $t_{i}$ is the occurrence time of the past seismic events, and $l_{i}$ is the length of rupture. The $R_{l t r}, T_{l t r}, L_{l t r}$ are the long-term averages of these functions. By subtracting them, they eliminate the linear trends of the corresponding functions. $r_{o}$ is a coefficient that characterizes the diminishing influence of more distant seismic events; $t_{o}$ is the coefficient characterizing the rate at which the preceding seismic events are "forgotten" as the time of analysis moves on; and $p$ is the coefficient that characterizes the contribution of size of each preceding event. With $p=1,2$ or 3 , this quantity is proportional to source length, square of rupture, or the energy, respectively.

$R, T$ and $L$ are dimensionless functions. They are further normalized by their standard deviations, $\sigma_{R}, \sigma_{T}$, and $\sigma_{L}$, respectively. The product of the above three functions is calculated as the RTL-parameter, which describes the deviation from the background level of seismicity and is in units of the standard deviation, $\sigma=\sigma_{R} \sigma_{T} \sigma_{L}$.

$$
R T L=R(x, y, z, t) T(x, y, z, t) L(x, y, z, t) .
$$

Various combinations of the $R, T$ and $L$ functions have been tested when evaluating the algorithm RTL. The fluctuations of their product have been found to be highly sensitive to quiescence anomalies and to be characterized by low background noise.
A decrease of RTL means a decrease of seismicity compared to the background rate around the investigated place (a seismic quiescence). A recovery stage from the quiescence to the background level can be considered as foreshock activation (in a broad sense). The RTL-method evaluates both the seismic quiescence and the following stage of activation. In addition, the location of the maximum expression of an anomaly can be found by performing the RTL-calculations with the centers of the sampling circles at the nodes of a grid.

The original catalog for Sakhalin, prepared by the Geophysical Service of the RAS, contains the events characterized by energy class $K=\log E$, where $E$ is the seismic energy of the events in $J$. The length of rupture, $l_{i}$, in the $L$ function was calculated by the formula (Riznichenko, 1976).

$$
\log l(\mathrm{~km})=0.244 \log K-2.266 \text {. }
$$

\section{Quiescence Measured by Z-values \\ 5.1 The Neftegorskoe $M_{w}$ 7.6 earthquake of May 27, 1995}

The cumulative numbers of earthquakes as a function of time for a circle with $R=65 \mathrm{~km}$ centered in the middle of the 1995 aftershock area $\left(52.85^{\circ} \mathrm{N} / 142.9^{\circ} \mathrm{E}\right)$, as mapped by Katsumata et al. (2002) shows an anomaly of no earthquakes during the 2.7 years before the main shock (Fig. 2(a)). During the first 18.7 years, 57 earthquakes occurred, which averages to a rate of 3 events/year. Thus, during the 2.7 years preceding the Neftegorskoe shock, nine events are expected, but none was recorded. If the radius is increased beyond 65 $\mathrm{km}$, a couple of earthquakes are picked up during the last two years, and the pattern of quiescence is degraded. With $T_{w}=2.5$ years and $R=65 \mathrm{~km}$, the comparison of the seismicity rate during the last two years with the background rate results in $Z=6.7$. In this approach to identify the quiescence, we simply increased the radius of a circle around the center of the aftershock activity until the anomalous pattern was degraded.

In a second approach, we selected earthquakes inside a rectangle with two sides parallel to the Neftegorskoe rupture. For small dimensions of this rectangle, the sample was approximately the same as that selected by the circle and seen in Fig. 2(a). We then moved each side of the rectangle as far away from the epicenter as we could without degrading the pattern of precursory seismic quiescence. In this way, one finds that to the south, east and north the boundary can be moved quite far (rectangle in Fig. 1), without degrading the quiescence pattern (Fig. 2(b)). A single earthquake is picked up near 52N/143E during the last two years before the main shock. Toward the west, however, some earthquakes are picked up for this period from the cluster near $52.3 \mathrm{~N} / 142 \mathrm{E}$, degrading the pattern substantially. Hence we find the limits of the rectangle as shown in Fig. 1.

In this rectangle, with dimensions of 600 by $200 \mathrm{~km}$, 210 earthquakes were recorded during the first 17.7 years, on average 12 events/year. During the last 1.8 years, one earthquake was observed, instead of the 21 expected ones. With $T_{w}=1.5$ years, the comparison of the rate during the anomalous time to the background leads to $Z=10.0$.

Using the gridding approach, placing the grid at random, a maximum value of $Z=12.1$ was found for $N=150$ 

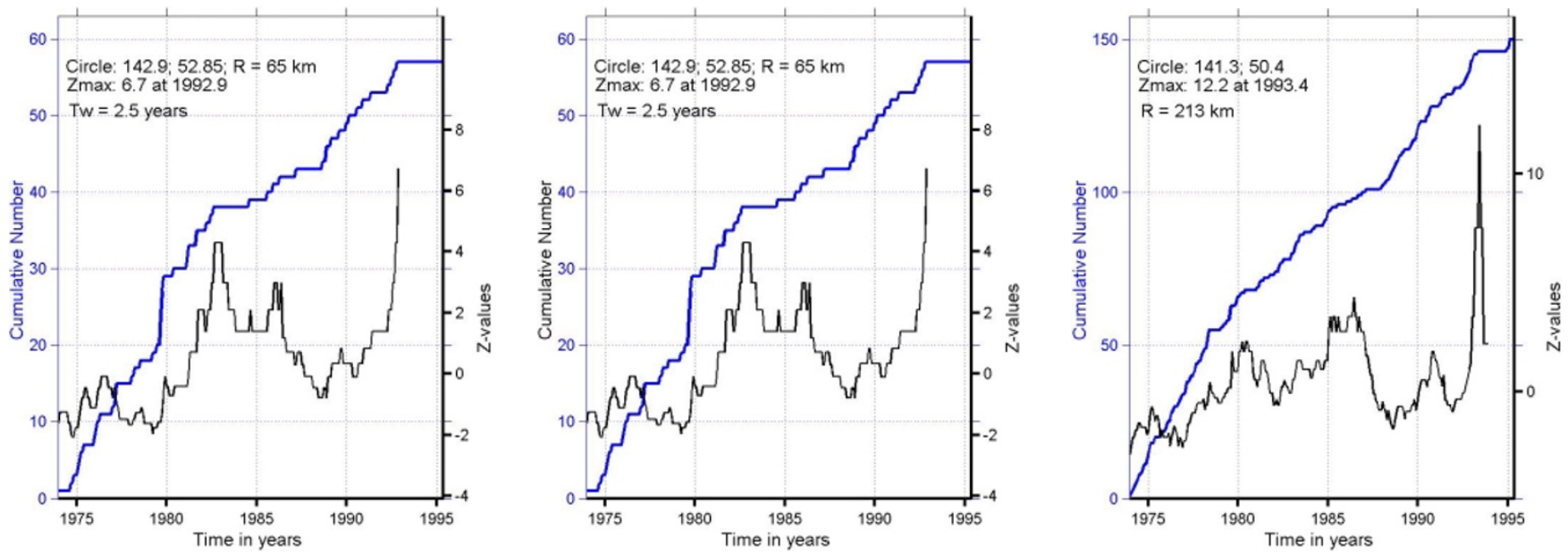

Fig. 2. Cumulative numbers of earthquakes (upper curves, scale on the left) with $M \leq 3.4$ as a function of time, up to the occurrence of the Neftegorskoe main shock in 1995.4. Lower curves show the $Z$-values (scale on the right), resulting from every position of the time window $T_{w}$. (A) Sample from a circle with $R=65 \mathrm{~km}$, centered in the middle of the aftershocks and $T_{w}=2.5$ years. (B) Sample from the rectangle shown in Fig. 1 and $T_{w}=1.5$ years. (C) One of the samples with $N=150$ showing highest significance.
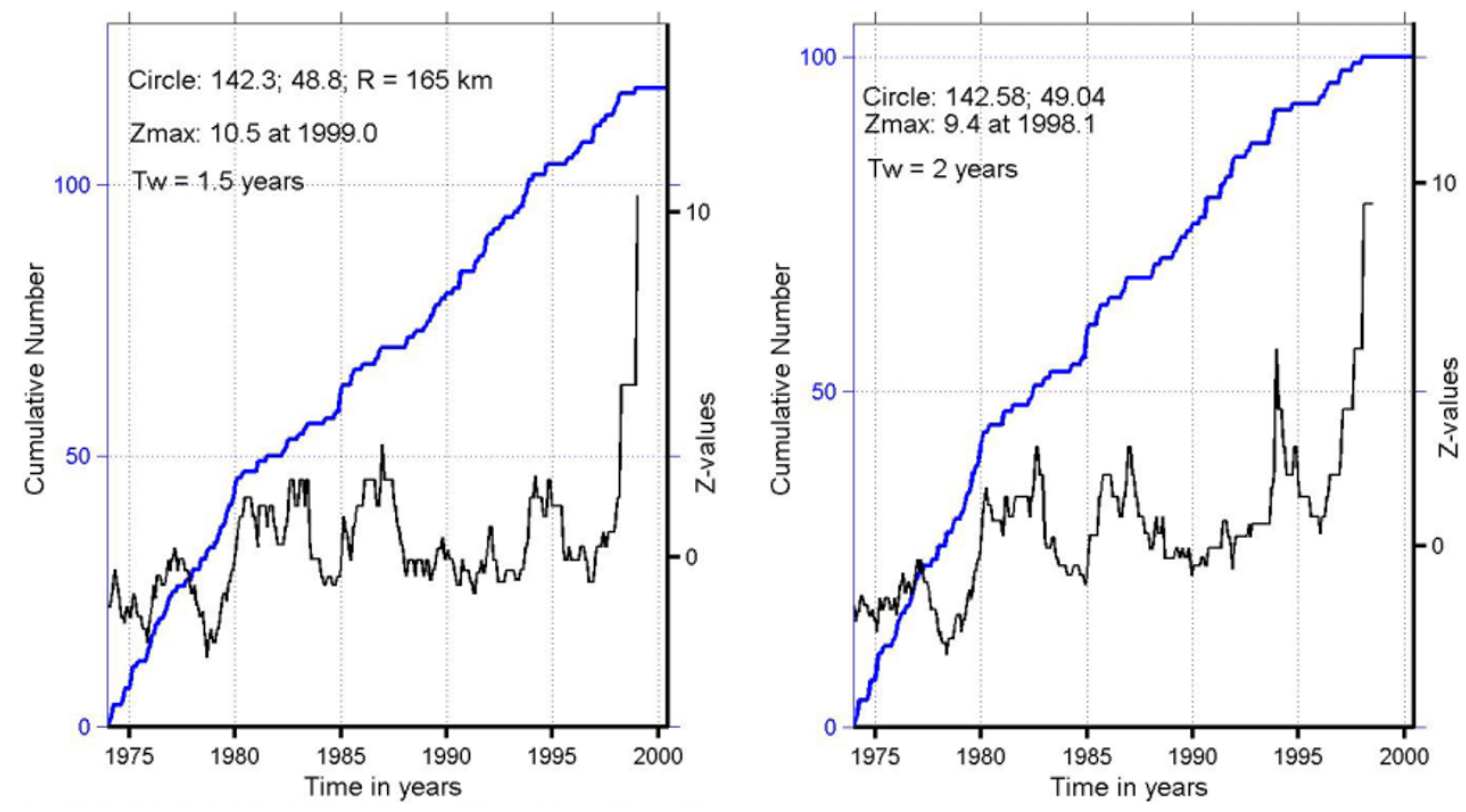

Fig. 3. Cumulative numbers (upper curves, scale at left) of earthquakes as a function of time before the $2000 M_{w} 6.8$ Uglegorskoe earthquake. Lower curve is the $Z$-value function for moving time windows (scale at right). (A) Data from a circle with $R=656 \mathrm{~km}$, centered at the epicenter. $T_{w}=1.5$ years. (B) One of the datasets highlighted in Fig. 4 as showing a highly significant precursory quiescence. $T_{w}=2$ years.

and $T_{w}=2$ years (Fig. 2(c)). There were only 3 nodes at which this maximum was observed. Only one position of $T_{w}$, namely just before the main shock, yielded this result. The positions of the three adjoining nodes with anomalous $Z$ values were such that they all sampled most of the rectangle shown in Fig. 1. In the array of $10^{6} \mathrm{Z}$-values generated for this grid with $n=150$, there were no competitors to the anomaly described above. The characteristics of this anomaly are summarized in Table 5 .

\subsection{The $M_{w} 6.8$ Uglegorskoe Earthquake of August 4, 2000}

The seismicity rate decrease and the $Z$-function before the 2000 Uglegorskoe earthquake are shown in two ways. Figure 3(a) shows the data in the circle centered at the epicenter with the largest radius $(R=165 \mathrm{~km})$ before the quies- cence pattern is degraded. Figure 3(b) shows the seismicity in one of the circles containing 100 events, located near the 2000 epicenter and found by mapping the $Z$-value with a randomly positioned grid (Fig. 4).

The $Z$-map of Fig. 4 was generated by a grid with $0.05^{\circ}$ and $0.025^{\circ}$ spacing in the longitudinal and latitudinal directions, respectively. For the analysis of the seismicity pattern before the 2000 main shock, the northern part of Sakhalin Island was not used because of the large numbers of aftershocks following the 1995 Neftegorskoe shock. Thus, the total number of events available for the period 1974-2000.6 was reduced to $N_{\text {tot }}(M \geq 3.4)=331$.

The red zone of highly significant change is located adjacent to the Uglegorskoe 2000 epicenter (Fig. 4). The position of this anomalous zone is not very stable; just a few earth- 

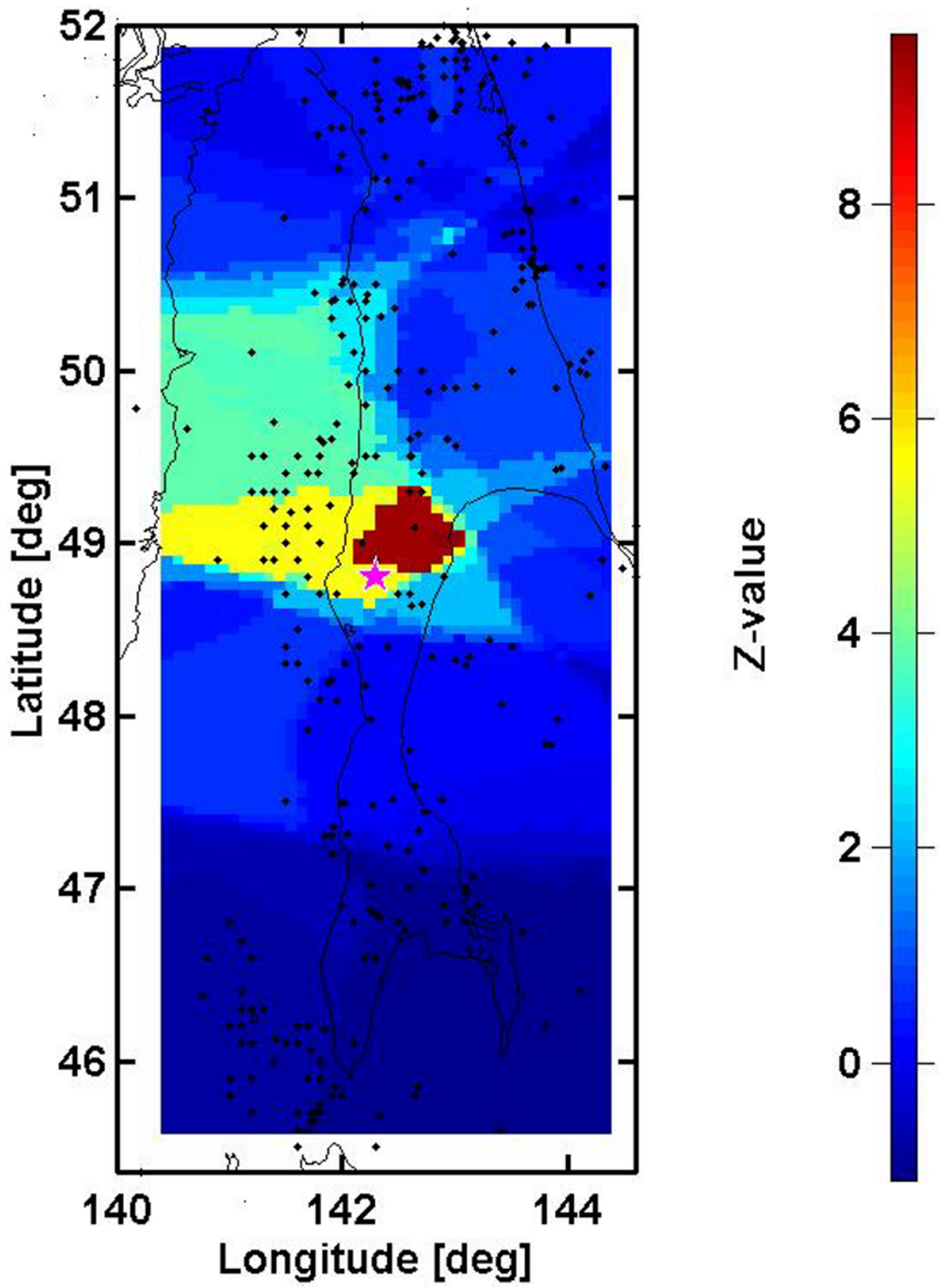

Fig. 4. Map of Z-values that result if the rate in the two years after 1998 is compared to the background rate before that time. For sampling, nodes were spaced 0.05 and 0.025 along the abscissa and ordinate respectively. At each node, the nearest 100 events were selected. Because of the low seismicity, the radii are typically 100 to $150 \mathrm{~km}$, overlapping each other to a large extent. This means that the samples for the red area come from latitudes 47.5 to 50.5, approximately. Dots mark epicenters. The star shows the epicenter of the 2000 Sakhalin main shock.

quakes can shift it by a few 10 s of kilometers. This instability is due to the relatively low seismicity rate in all of Sakhalin. In such a case, the occurrence of a few events can degrade the significance of rate change.

Both examples of cumulative seismicity curves show very clear quiescence during the 1.5 to 2.5 years before the 2000 main shock (Fig. 3). In the circle centered at the epicenter, 117 events occurred during the first 25 years, yielding a mean rate of 4.9 events/year. Thus, 12 earthquakes are expected during the 2.5 years before the main shock, but only one was observed. The parameters of this anomaly are summarized in Table 6.

\section{Quiescence Measured by the RTL-Algorithm \\ 6.1 The Neftegorskoe $M_{w} 7.6$ earthquake of May 27, 1995}

Figure 5 (curve A) shows the temporal variation of the RTL-parameter at the center of the aftershocks $\left(52.85^{\circ} \mathrm{N} / 142.9^{\circ} \mathrm{E}\right)$. The events used were located in a circle around this point and satisfied the following criteria: en- 


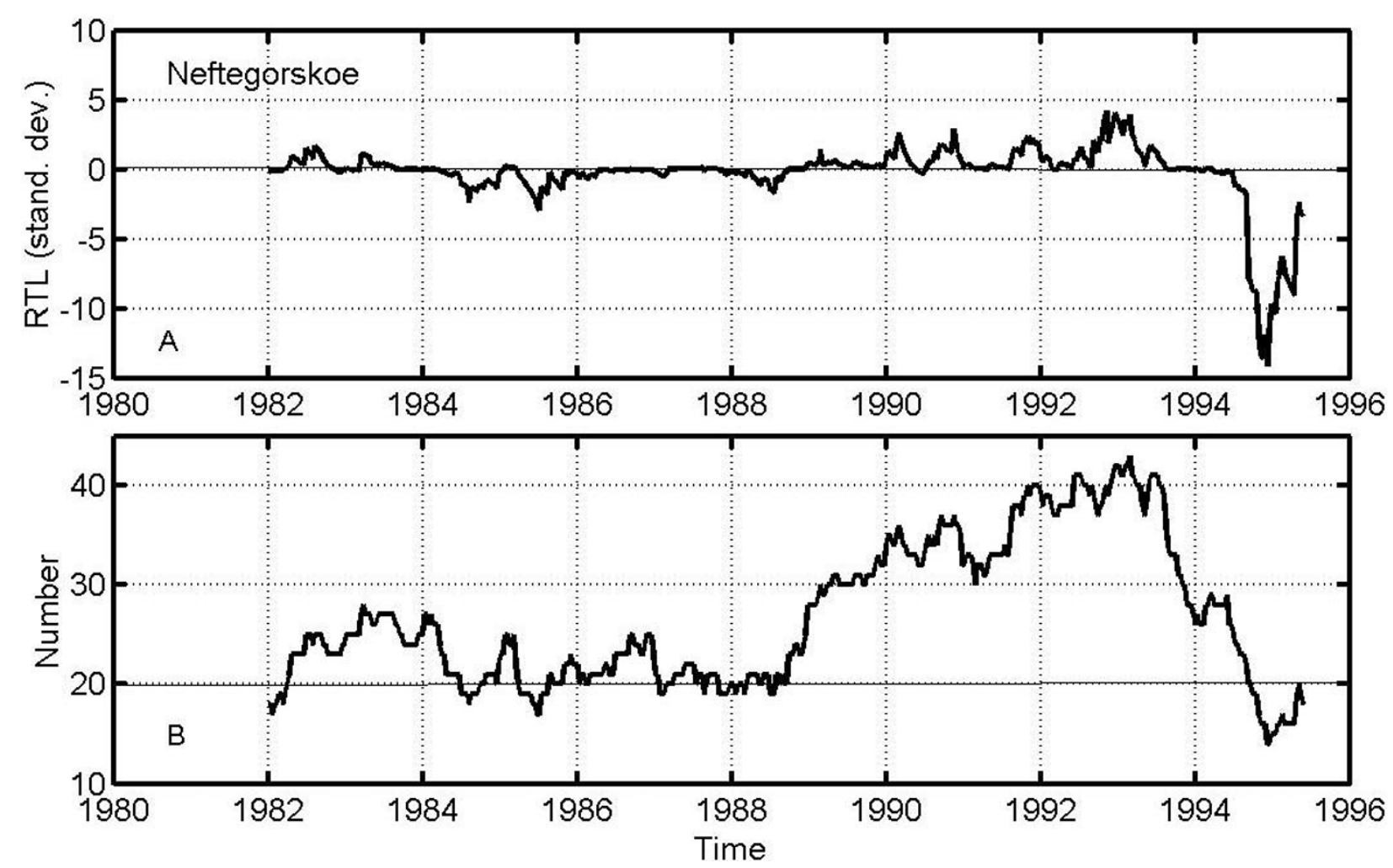

Fig. 5. The temporal variation of (A) the RTL parameter and (B) number of earthquakes at the point $\left(142.9^{\circ} \mathrm{E}, 52.85^{\circ} \mathrm{N}\right)$ in the middle of aftershocks of the Neftegorskoe main shock in 1995.4. All events were located in the circle around this point and satisfied the following criteria: energy class $K_{\text {min }} \geq 8.0$, focal depth $H \leq 80 \mathrm{~km}$, epicentral distance $r_{i} \leq R_{\max }=2 r_{o}=400 \mathrm{~km}$, and time interval $\left(t-t_{i}\right) \leq T_{\max }=2 t_{o}=2$ years.

ergy class $K_{\min } \geq 8.0$, focal depth $H \leq 80 \mathrm{~km}$, epicentral distance $r_{i} \leq R_{\max }=2 r_{o}=400 \mathrm{~km}$, and time interval $\left(t-t_{i}\right) \leq T_{\max }=2 t_{o}=2$ years. The typical signal of a seismic quiescence was obtained from this RTL-curve, followed by a significant activation stage. The RTL-curve remained near zero from its first value in 1982, until quiescence started in September 1994 and reached its bottom in December 1994 (Fig. 5). The strongest deviation from the background was $-14.1 \sigma$. During the critical period, the $R$, $T$, and $L$ functions attained the values $-2.4,-2.45,-2.4$, respectively. Figure 5 (curve B) demonstrates the variations of the number of earthquakes, which participated in the RTLcalculation (201 events total) in the moving time window $T_{\text {max }}=2$ years.

To check the reliability of the RTL-anomaly, we changed the threshold of $K_{\min }$ and the free parameters $r_{o}, t_{o}$ of equation (2). The anomaly was clearly present with all reasonable choices of these parameters. Increasing $K_{\min }$ to 8.5 (Fig. 6, A1), or decreasing $R_{\max }$ to $200 \mathrm{~km}$ (Fig. 6, A2), slightly diminishes the amplitude of the anomaly. This is probably due to poor statistical resolution because fewer earthquakes are available to define the background rate (113 and 130 events, respectively). Increasing $R_{\max }$ to $600 \mathrm{~km}$ (Fig. 6, A3) did not significantly change the RTL-anomaly presented in Fig. 5. The minor influence of changing $T_{\max }=2 t_{o}$ to 1 or 4 years is demonstrated in Fig. 6(b). In both of these curves, the precursory quiescence anomaly is highly significant and unique. Only the onset in time is somewhat shifted when different time windows are used for analysis.

In an effort to define the geographical extent of the anomaly, the RTL-parameter was calculated in cells of a geographic net with a $15 \mathrm{~km}$ node spacing. At each node, the sampling parameters were the same as in Figs. 5-8. The results suggest that the anomaly had dimensions of about 100 $\mathrm{km}$ in the N-S direction and was centered adjacent to northwest of the Neftegorskoe epicenter. However, because of the low seismicity rate, the mapping of RLT is not very reliable.

\subsection{The $M_{w} 6.8$ Uglegorskoe Earthquake of August 4,} 2000

We applied the same procedure (Eq. (2)) to process the seismicity variations before the Uglegorskoe earthquake of August 4, 2000, using the same parameters for the RTLalgorithm.

Figure 7 (graph A) shows the temporal variation of the RTL-parameter at the epicenter of main shock $\left(48.80^{\circ} \mathrm{N} / 142.3^{\circ} \mathrm{E}\right)$. All events counted were located in a circle around this point and satisfied the following criteria: energy class $K_{\min } \geq 8.0$, focal depth $H \leq 80 \mathrm{~km}$, epicentral distance $r_{i} \leq R_{\max }=2 r_{o}=400 \mathrm{~km}$, and time interval $\left(t-t_{i}\right) \leq T_{\max }=2 t_{o}=2$ years. The RTL-curve showed an apparent seismic quiescence in this case also (graph A, Fig. 7), followed by an activation stage. The quiescence started in May 1999 and reached its bottom in November 1999. The most significant deviation from the background was $-10.2 \sigma$. During this anomalous period, the $R, T$, and $L$ functions attained the values $-1.9,-2.5,-2.1$, respectively. Figure 7 (graph B) demonstrates the variations of the number of earthquakes, which participated in the RTL-calculation (231 events) in a moving time window of $T_{\max }=2$ years. Two other quiescence anomalies, with significances similar 

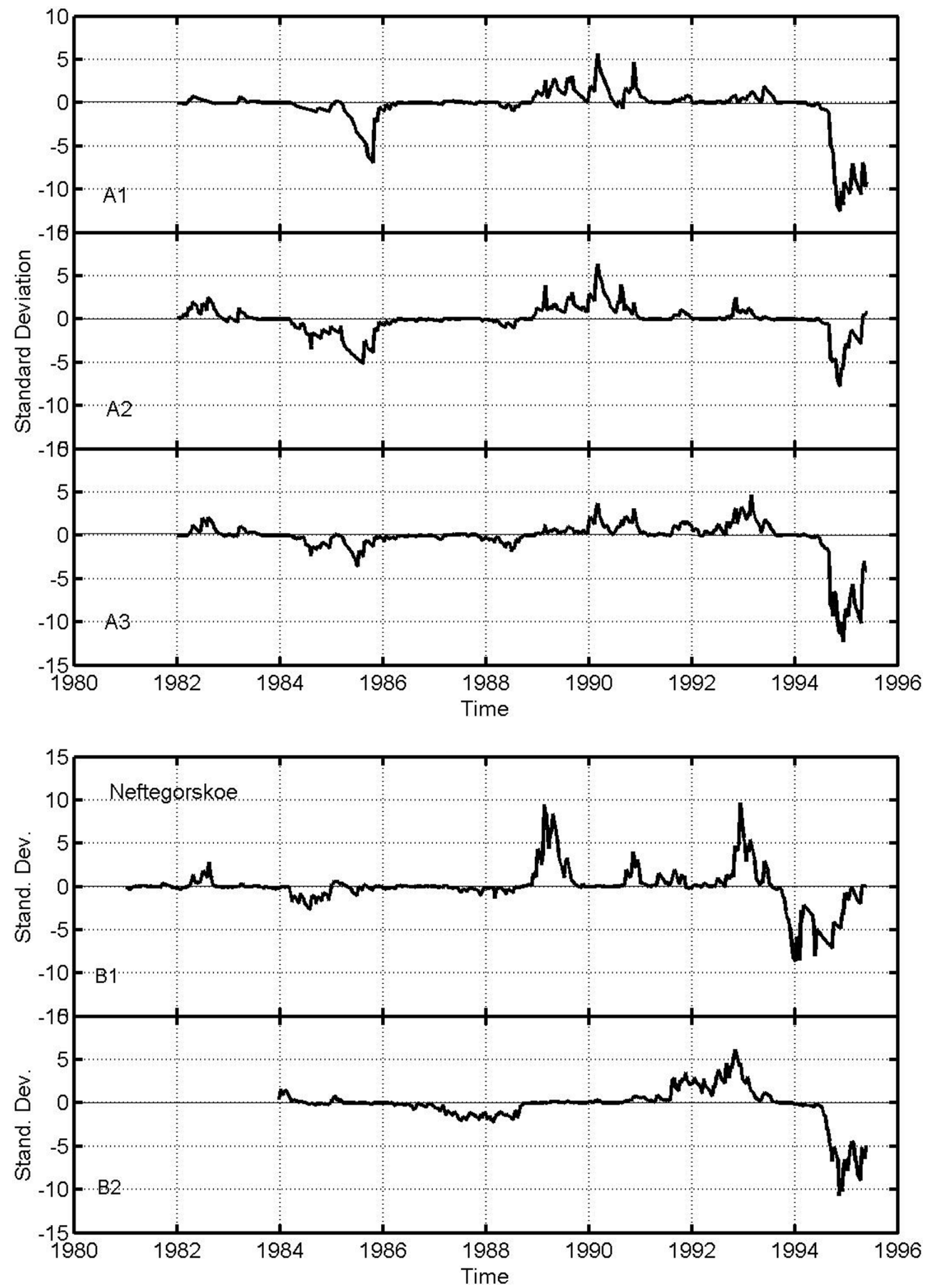

Fig. 6. (A) The temporal variations of the RTL parameter at the point $\left(142.9^{\circ} \mathrm{E}, 52.85^{\circ} \mathrm{N}\right)$ in the middle of aftershocks of the Neftegorskoe main shock in 1995.4: (A1) $-K_{\min } \geq 8.5, H \leq 80 \mathrm{~km}, R_{\max }=400 \mathrm{~km}, T_{\max }=2$ years; (A2) - $K_{\min } \geq 8.0, H \leq 80 \mathrm{~km}, R_{\max }=200 \mathrm{~km}, T_{\max }=2$ years; (A3) $K_{\min } \geq 8.0, H \leq 80 \mathrm{~km}, R_{\max }=600 \mathrm{~km}, T_{\max }=2$ years. (B) The temporal variations of the RTL parameter at the point $\left(142.9^{\circ} \mathrm{E}, 52.85^{\circ} \mathrm{N}\right)$ in the middle of aftershocks of the Neftegorskoe main shock in 1995.4: (B1) - $K_{\min } \geq 8.0, H \leq 80 \mathrm{~km}, R_{\max }=400 \mathrm{~km}, T_{\max }=1 \mathrm{year}$; (B2) - $K_{\min } \geq 8.0$, $H \leq 80 \mathrm{~km}, R_{\max }=400 \mathrm{~km}, T_{\max }=4$ years. 

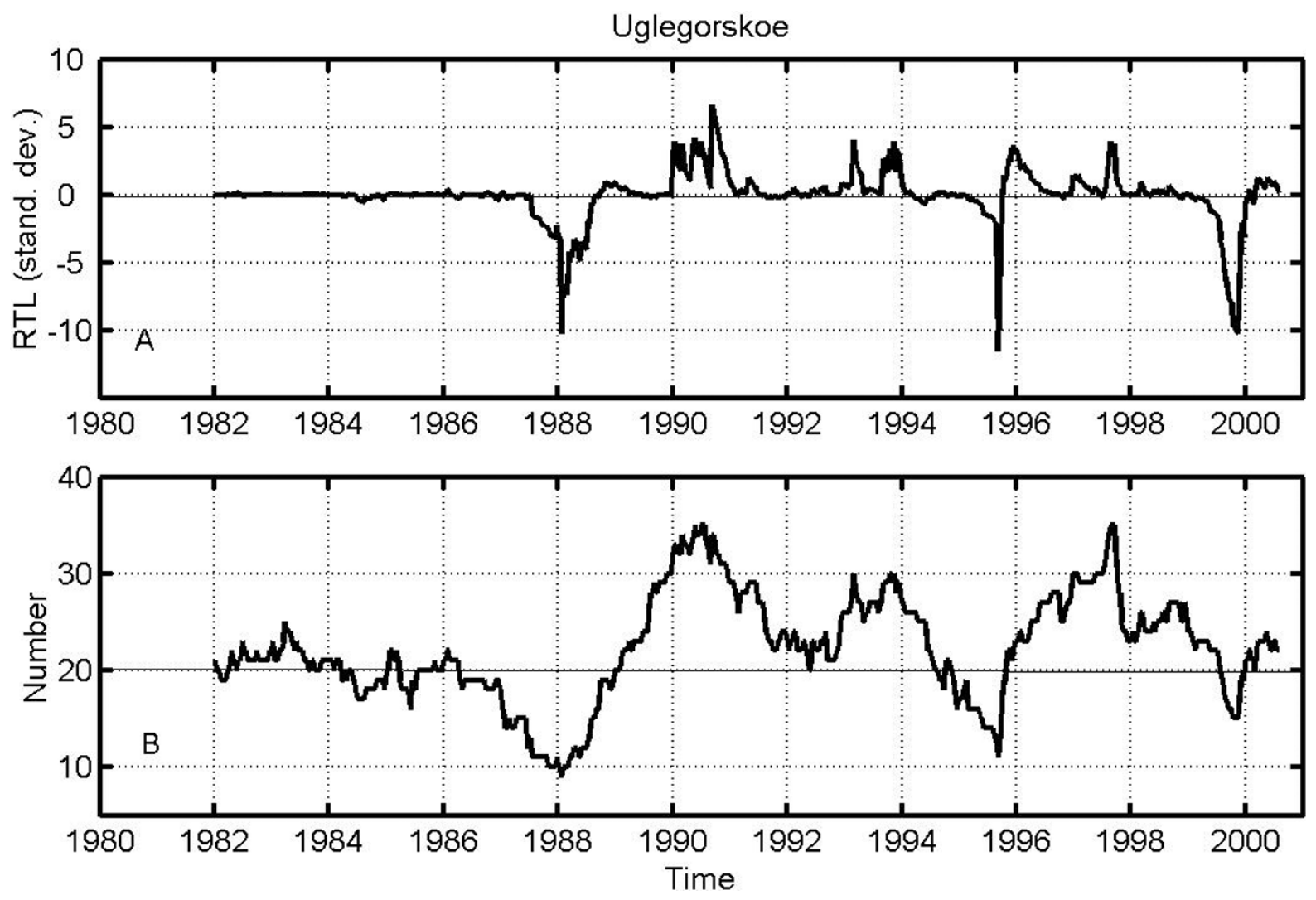

Fig. 7. The temporal variation of (A) the RTL parameter and (B) number of earthquakes at the point $\left(142.3^{\circ} \mathrm{E}, 48.80^{\circ} \mathrm{N}\right)$ at the epicenter of the Uglegorskoe main shock in 2000.6. All events were located in the circle around this point and satisfied following criteria: energy class $K_{\text {min }} \geq 8.0$, focal depth $\mathrm{H} \leq$ $80 \mathrm{~km}$, epicentral distance $r_{i} \leq R_{\max }=2 r_{o}=400 \mathrm{~km}$, and time interval $\left(t-t_{i}\right) \leq T_{\max }=2 t_{o}=2$ years.

to the 1999 precursor, are seen on this RTL-graph. The first one (in 1987/88) may be connected with a change of reporting style in the catalog, mentioned earlier. The second one (in 1995) occurred just after the Neftegorskoe earthquake.

To check the stability of the RTL-results in the Uglegorskoe case, we calculated the results when changing the $K_{\text {min }}$ threshold and the free parameters $r_{o}, t_{o}$ of Eq. (2). Increasing $K_{\min }$ to 8.5 (Fig. 8, A1) or decreasing $R_{\max }$ to $200 \mathrm{~km}$ (graph A2), slightly diminished the amplitude of the anomaly, again probably owing to poor statistical resolution by fewer earthquakes in the data sets (128 and 108 events, respectively). Increasing $R_{\max }$ to $600 \mathrm{~km}$ (Fig. 8, A3) increases the amplitude of the anomaly in 1999 to a uniquely high significance. With windows of $T_{\max }=1$ or 4 years, the precursor anomaly in 1999 becomes even more significant and unique (Fig. 8(b)). These results confirm the stability of our estimates of the 1999 quiescence anomaly.

The attempt to map the RTL-anomaly before the Uglegorskoe earthquake, using the same technique as in the Neftegorskoe case, suggests that the dimensions were about $200 \mathrm{~km}$, and the anomaly minimum was located at and to the southwest of the epicenter.

\section{Estimating the Significance of the Results}

The statistical significance of the observed anomalies were estimated in both methods by generating synthetic catalogs with the same properties as the data at hand and then performing the analysis numerous times to see how often results with the observed significance level occurred by chance. Al- though we measured the deviation from normal of the RTL function by its standard deviation, the probability of RTL anomalies by chance is estimated using randomly generated catalogs (Tables).

In the case of the RTL-method, the probability of random occurrence of the two observed anomalies was evaluated as follows. First, we determined the characteristics of the Sakhalin catalog in the period of 01.01.1980-26.05.1995, with coordinates of $49.30^{\circ} \mathrm{N} \leq \varphi \leq 55.23^{\circ} \mathrm{N}, 140.17^{\circ} \mathrm{E} \leq$ $\lambda \leq 145.00^{\circ} \mathrm{E}$ and focal depth $H \leq 80 \mathrm{~km}$ (surrounding the hypocenter of the Neftegorskoe earthquake). We found that there are 210 earthquakes with energy class ranging from 8.0 to 11.7. The annual average number of earthquakes was $N_{o}=13$ events/year, with a standard deviation of $D=$ 5. Based on this distribution, we calculate the occurrence probability, $P$, of earthquakes with different energy classes (Table 1).

Next, we compiled synthetic catalogs in the following way: (a) Coordinates of earthquake hypocenters were generated randomly in the volume defined above. (b) The annual number of events was selected randomly in the interval $\left[N_{o}-D, N_{o}+D\right]$, using a uniform distribution. (c) Energy classes of earthquakes were assigned randomly; according to the probability of occurrence in the real catalog (see Table 1).

For each synthetic catalogue, we calculated the RTLparameter at the point of the Neftegorskoe earthquake epicenter, choosing the same parameters, which were used in the calculations for the real catalog. For the synthetic catalogs, we defined a 'quiescence anomaly' by the following 

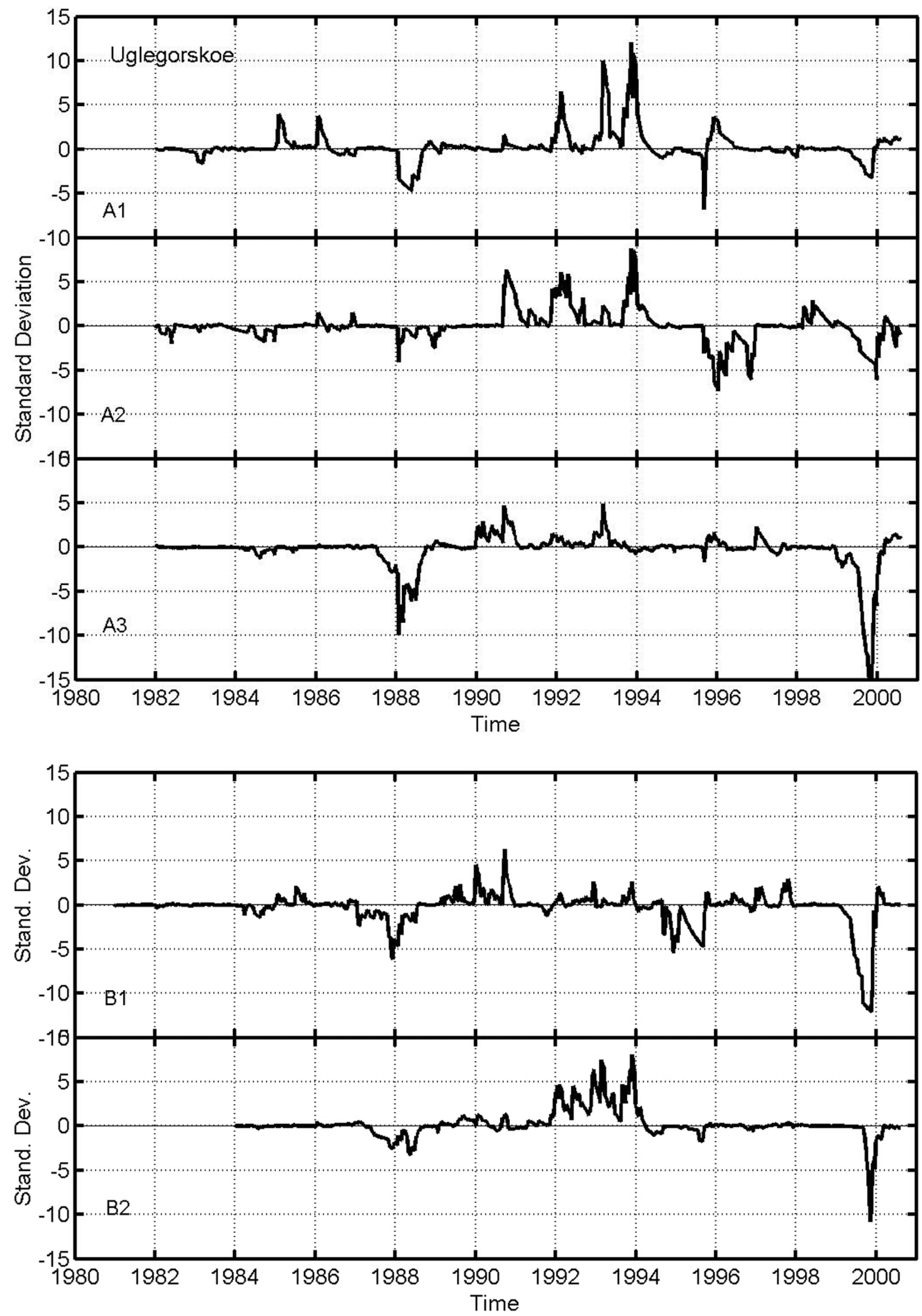

Fig. 8. (A) The temporal variations of the RTL parameter at the point $\left(142.3^{\circ} \mathrm{E}, 48.80^{\circ} \mathrm{N}\right)$ at the epicenter of the Uglegorskoe main shock in 2000.6 : $(\mathrm{A} 1)$ $-K_{\min } \geq 8.5, H \leq 80 \mathrm{~km}, R_{\max }=400 \mathrm{~km}, T_{\max }=2$ years; $(\mathrm{A} 2)-K_{\min } \geq 8.0, H \leq 80 \mathrm{~km}, R_{\max }=200 \mathrm{~km}, T_{\max }=2$ years; $(\mathrm{A} 3)-K_{\min } \geq 8.0$, $H \leq 80 \mathrm{~km}, R_{\max }=600 \mathrm{~km}, T_{\max }=2$ years. (B) The temporal variations of the RTL parameter at the point $\left(142.3^{\circ} \mathrm{E}, 48.80^{\circ} \mathrm{N}\right)$ at the epicenter of Uglegorskoe main shock in 2000.6: (B1) $-K_{\min } \geq 8.0, H \leq 80 \mathrm{~km}, R_{\max }=400 \mathrm{~km}, T_{\max }=1$ year; (B2) $-K_{\min } \geq 8.0, H \leq 80 \mathrm{~km}, R_{\max }=400 \mathrm{~km}$, $T_{\max }=4$ years 
Table 1. Probability of occurrence of earthquakes in the area surrounding the Neftegorskoe earthquake.

\begin{tabular}{|c|c||c|c|}
\hline $\mathrm{K}$ & $\mathrm{P}$ & $\mathrm{K}$ & $\mathrm{P}$ \\
\hline 8.0 & 0.1276 & 9.9 & 0.0104 \\
8.1 & 0.0781 & 10.0 & 0.0130 \\
8.2 & 0.0755 & 10.1 & 0.0078 \\
8.3 & 0.0651 & 10.2 & 0.0078 \\
8.4 & 0.0755 & 10.3 & 0.0026 \\
8.5 & 0.0703 & 10.4 & 0.0000 \\
8.6 & 0.0651 & 10.5 & 0.0000 \\
8.7 & 0.0521 & 10.6 & 0.0026 \\
8.8 & 0.0365 & 10.7 & 0.0026 \\
8.9 & 0.0495 & 10.8 & 0.0000 \\
9.0 & 0.0417 & 10.9 & 0.0026 \\
9.1 & 0.0391 & 11.0 & 0.0052 \\
9.2 & 0.0521 & 11.1 & 0.0026 \\
9.3 & 0.0339 & 11.2 & 0.0000 \\
9.4 & 0.0208 & 11.3 & 0.0000 \\
9.5 & 0.0182 & 11.4 & 0.0000 \\
9.6 & 0.0130 & 11.5 & 0.0000 \\
9.7 & 0.0156 & 11.6 & 0.0026 \\
9.8 & 0.0078 & 11.7 & 0.0026 \\
\hline
\end{tabular}

Table 2. Probability of RTL-anomaly before the Neftegorskoe earthquake by chance.

\begin{tabular}{|c|c|}
\hline $\begin{array}{c}\text { Duration W } \\
\text { (years) }\end{array}$ & Probability P \\
\hline 0.5 & 0.015000 \\
0.7 & 0.009250 \\
0.9 & 0.004250 \\
1.1 & 0.001250 \\
1.3 & 0.000250 \\
1.5 & 0.000000 \\
1.7 & 0.000000 \\
1.9 & 0.000000 \\
2.1 & 0.000000 \\
2.3 & 0.000000 \\
\hline
\end{tabular}

two conditions. (1) A minimum RTL-value of below 10 standard deviations is reached $(R T L \leq-10 \sigma)$. (2) The duration of the anomaly, $\mathrm{W}$, is the interval during which the RTL-value remains below minus two standard deviations $(R T L \leq-2 \sigma)$. Then, we calculated the RTL-parameters for 4000 random catalogs and estimated the occurrence probability of an RTL-anomaly with the aforementioned properties for these random catalogues. The result is shown in Table 2.

In the real case of the Neftegorskoe earthquake, we obtained an RTL-anomaly with a minimum of $-14.13 \sigma$ and duration of about 0.7 years. Therefore, we can conclude from Table 2 that the probability of such an RTL-anomaly occuring by chance is less than 0.01. Namely, the RTLanomaly in 1994-1995 is not likely due to chance.

For the Uglegorskoe earthquake, we analyzed the Sakhalin catalog the same way for an interval of 01.01.198004.08.2000 with coordinates of $45.50^{\circ} \mathrm{N} \leq \varphi \leq 52.37^{\circ} \mathrm{N}$, $140.17^{\circ} \mathrm{E} \leq \lambda \leq 144.61^{\circ} \mathrm{E}$ and focal depth $H \leq 80 \mathrm{~km}$
Table 3. Probability of occurrence of earthquakes of in the area surrounding the Uglegorskoe earthquake.

\begin{tabular}{|c|c||c|c|}
\hline $\mathrm{K}$ & $\mathrm{P}$ & $\mathrm{K}$ & $\mathrm{P}$ \\
\hline 8.0 & 0.1119 & 9.9 & 0.0163 \\
8.1 & 0.0956 & 10.0 & 0.0093 \\
8.2 & 0.0956 & 10.1 & 0.0070 \\
8.3 & 0.0676 & 10.2 & 0.0070 \\
8.4 & 0.0723 & 10.3 & 0.0000 \\
8.5 & 0.0816 & 10.4 & 0.0047 \\
8.6 & 0.0676 & 10.5 & 0.0047 \\
8.7 & 0.0536 & 10.6 & 0.0000 \\
8.8 & 0.0443 & 10.7 & 0.0000 \\
8.9 & 0.0466 & 10.8 & 0.0000 \\
9.0 & 0.0536 & 10.9 & .0047 \\
9.1 & 0.0326 & 11.0 & 0.0070 \\
9.2 & 0.0186 & 11.1 & 0.0023 \\
9.3 & 0.0163 & 11.2 & 0.0023 \\
9.4 & 0.0186 & 11.3 & 0.0023 \\
9.5 & 0.0140 & 11.4 & 0.0000 \\
9.6 & 0.0117 & 11.5 & 0.0000 \\
9.7 & 0.0140 & 11.6 & 0.0023 \\
9.8 & 0.0117 & 11.7 & 0.0023 \\
\hline
\end{tabular}

Table 4. Probability of RTL-anomaly before the Uglegorskoe earthquake by chance.

\begin{tabular}{|c|c|}
\hline $\begin{array}{c}\text { Duration W } \\
\text { (years) }\end{array}$ & $\mathrm{P}$ \\
\hline 0.5 & 0.018250 \\
0.7 & 0.013250 \\
0.9 & 0.008500 \\
1.1 & 0.003750 \\
1.3 & 0.002000 \\
1.5 & 0.001000 \\
1.7 & 0.000250 \\
1.9 & 0.000000 \\
2.1 & 0.000000 \\
2.3 & 0.000000 \\
\hline
\end{tabular}

(around the hypocenter of the 2002 main shock). We found that there are 231 earthquakes with energy classes ranging from 8.0 to 11.7. The annual average number of earthquakes was $N_{o}=11$ with a variance of $D=4$. Table 3 gives the occurrence probability of earthquakes with different energy classes.

The estimated probability of an RTL-anomaly by chance for 4000 random catalogs is presented in Table 4.

In the real case of the Uglegorskoe earthquake, we obtained an RTL-anomaly with a minimum of $-10.23 \sigma$ and duration of 0.5 years. Therefore, we can conclude from Table 4 that the probability for the observed RTL-anomaly to occur by chance is less than 0.02 . Namely, the RTL-anomaly in 1999 is not likely to have occurred by chance.

In the $Z$-value method, we ask not only the question "What is the statistical significance of the $Z$-value scored by 


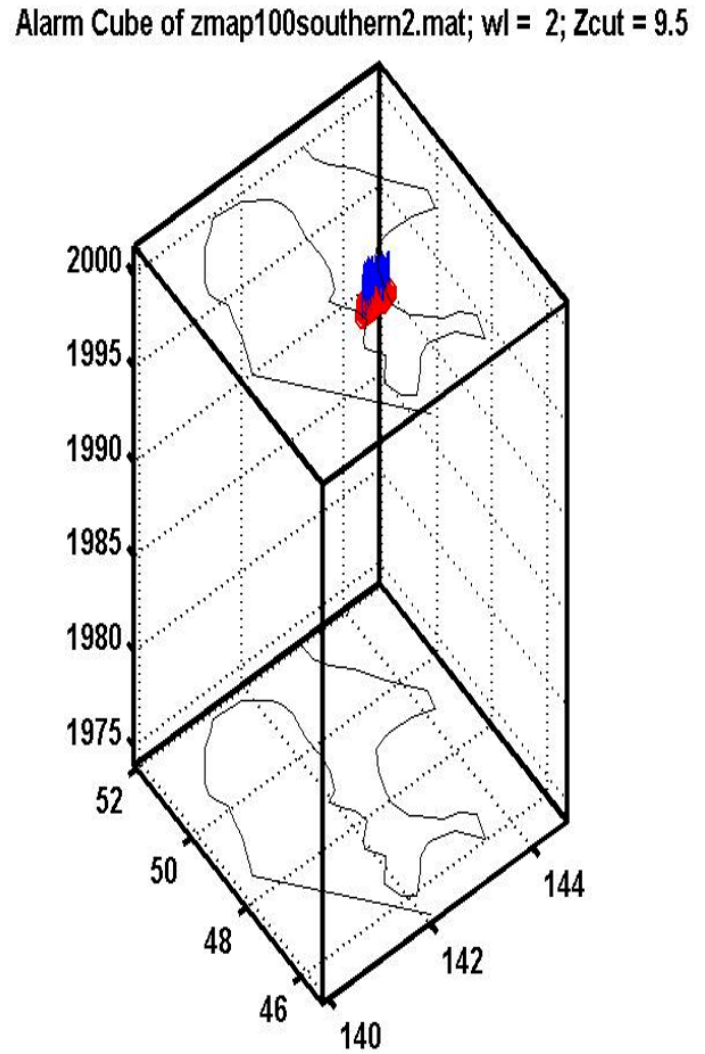

Fig. 9. Alarm cube with $T_{w}=2$ years and $N=100$ events at each node, in which the time at each node is marked (circle), if $Z \leq 9$.4. The duration of the time window is indicated by a vertical bar. In this 3 -D presentation, the two horizontal axes are the latitude and longitude, the vertical axis shows time. For this $Z$-level, only one alarm-group is seen, located near the 2000 main shock epicenter and during the period just before it. The rest of the volume of time and space does not show a single anomaly, although more than $105 \mathrm{Z}$-value estimates exist.

the proposed precursor anomaly?" but also "How often does a similarly significant quiescence happen without a main shock following it?" This second question addresses the possibility that transients in the Earth may cause instances of quiescence without following main shocks. To answer the first question, we also generate synthetic catalogs and simulate the experiment many times, using the same parameters as in the real catalog. The only difference to the RTL-method is that we do not pay attention to the magnitude distribution in the catalog, because this parameter is not used in the $Z$ map approach. To answer the second question, we search the results from the real catalog for episodes of highly significant quiescence at locations and times that are not related to main shocks. This is easily possible because we generated an array of $Z$-values that compare the rate within all 2 -year windows, and at every possible position in time, to the background rate, at about 1000 locations.

For the probability that the two anomalies are observed by chance, the routines programmed in ZMAP version 5 (Wiemer, 2001) also calculate values between $1 \%$ and $2 \%$. For a graphical presentation of the answer to the second question, ZMAP generates an alarm cube image (Fig. 9). For this 3-D presentation, one selects an 'alarm-level,' the $Z$-value above which one wishes to see the position in space and times of all occurrences. For both Sakhalin main shocks, the alarm cubes show only the anomaly just before the respective main shocks (e.g. Fig. 9), if the alarm level is set high. This means that in both cases no alarms exist that rival the precursory alarm in statistical significance.

\section{Discussion}

The data quality is satisfactory from the point of view of homogeneous reporting. We detected a change in the reporting procedure at the beginning of 1980 that disturbed the RTL-algorithm and reduced the significance of the $Z$ value analysis. This was caused by the change to reporting all decimal $K$-classes after 1980.0 , whereas before classes were given in bins of 0.5 units only. Another change of reporting appears to have happened in 1988.0, affecting mainly the southern part of Sakhalin Island. The cause of this apparent change is not known.

Visual inspection of the two quiescence anomalies is subjectively striking. The cumulative number plots in Figs. 2 and 3 climb at an approximately steady rate until the seismicity stops completely during the last 2.5 years. Quantitative measurements of the significance and the uniqueness of these observations are necessary, however, to establish them as significant anomalies. The first step toward establishing the statistical significance is the calculation of the parameters lta (Figs. 2 and 3) and RTL (Figs. 5, 6, 7 and 8) by the two methods employed here, respectively. These curves show that the quiescence anomalies in 1994 in the north and in 1999 in the south are very clearly defined by the algorithms.

The statistical significance of the two seismic quiescence anomalies in northern and southern Sakhalin is finally established at the $98 \%$ to $99 \%$ confidence level by calculating the probability that they may occur by chance in data sets artificially generated and modeled on the real data set (Tables 2 and 4). Some of the assumptions made for estimating these significance levels are approximations. This means that the exact level of significance could be challenged on the grounds that different assumptions should be used. Nevertheless, it is clear that at the very high significances we calculate, other reasonable assumptions will also lead to high significances. In addition, we investigate the uniqueness of the anomalies, below. If those anomalies have never happened at any time and in any volume, then we make a generic argument that these excursions from the mean are not normal. These two lines of reasoning together make a strong case that the phenomenon of anomalous quiescence is real.

The uniqueness of the anomalies is established by a search in all of Sakhalin and during all of time (covered by the catalog) for periods of quiescence with similar statistical significance as the two anomalies discussed above. In the $Z$ map method, the search was performed using the grid with $20 \mathrm{~km}$ node separation and moving the window by steps of three months. In the RTL-method, the node separation was $100 \mathrm{~km}$. Neither method detected any other anomaly with anywhere near the significance of that observed before the Neftegorskoe earthquake. For the Uglegorskoe anomaly, the RTL-method found one false alarm with a value of -10.5 sigma (compared to the precursor anomaly in 2000 of -10.2 sigma). This false RTL-alarm is seen in Figs. 7 and 8 in 1987. The RTL-method detected no other anomalies with values less than -5 sigma. Using the Zmap method, the 
Table 5. Characteristics of Neftegorskoe Precursory Quiescence.

\begin{tabular}{|c|l|c|c|c|}
\hline Method & \multicolumn{1}{|c|}{ Dimensions } & $\begin{array}{c}\text { Uncertainty } \\
\text { Dimensions }\end{array}$ & $\begin{array}{c}\text { Duration } \\
\text { (years) }\end{array}$ & $\begin{array}{c}\text { Uncertainty } \\
\text { Duration }\end{array}$ \\
\hline RTL & $\begin{array}{l}R=100 \text { to } 400 \mathrm{~km} \\
\text { around epicenter }\end{array}$ & $100 \mathrm{~km}$ & 2.7 & 0.5 years \\
\hline $\mathrm{Z}$ & $\begin{array}{l}\text { Rectangle } 200 \times 600 \mathrm{~km} \text { (Fig. 1) } \\
\text { containing source }\end{array}$ & $100 \mathrm{~km}$ & 2.7 & 0.5 years \\
\hline
\end{tabular}

alarm cube (Fig. 9) shows that there are no competitors for the Uglegorskoe quiescence anomaly, the same as for the Neftegorskoe earthquake. Therefore, we conclude that there existed two highly significant periods of seismic quiescence in Sakhalin Island (during the period of the earthquake cata$\log$ of good quality, i.e. since 1974). One of these, in 1994, was more significant than any other period of low activity, as judged by both methods. The other anomaly, in 2000, was unique in significance as measured by the Z-test, but tied by a second period of low activity in 1987, as measured by the RTL-algorithm.

The correlation of these two quiescence anomalies with the only two large main shocks in Sakhalin during this period is strongly suggested by four observations concerning their location in time and space. (1) Both anomalies occurred during the periods immediately prior and up to the two main shocks (Figs. 2, 3, 5, 6, 7, and 9). (2) In both cases, volumes centered at the epicenters (and alternatively at the center of the aftershock area) showed the anomalies clearly (Figs. 2(a), 3(a), 5, 6, and 8). (3) The volumes mapped by both methods as the locations of the strongest quiescence anomalies, contained the source volumes of the two main shocks (e.g. circles containing $N=100$ events and centered anywhere within the red zone of Fig. 4 all contained the epicenter of the Uglegorskoe main shock). (4) No quiescence anomalies occurred with significance approaching the Neftegorskoe case anywhere else in space and time. The anomaly before the Uglegorskoe earthquake was also clearly uniquely significant, as measured by the $Z$-test, but it was approximately equal to an anomaly in 1987, as measured by the RTL-method. Thus, we conclude that the two quiescence anomalies, which we documented and evaluated, were precursors to the only two large main shocks to occur in Sakhalin Island during the last three decades and that, on rare occasions, false alarms may equal such precursors in significance.

The properties of these two precursory quiescences are summarized in Tables 5 and 6 . The estimates of both, the duration and the spatial extent, contain uncertainties, which depend on the approach taken in the analysis and on the quality of the data set. In the present cases, these uncertainties are larger than in some other areas because of the relatively sparse data set. The anomaly duration is defined as the period between the onset of the quiescence and the main shock. In the RTL-method the onset of the anomaly is defined as the time at which the RTL-algorithm passes below $-2 \sigma$. Because the RTL-value is plotted at the end of a time window of two years, the data set that first gives rise to the value of $-2 \sigma$ begins two years before the point on the graphs where this value is plotted. In the $Z$-method, the beginning of the anomaly is defined as the time at which the lta-function first reaches its maximum. This turns out to be identical as requiring a rate decrease of more than $95 \%$, in the present cases.

The two different approaches yielded very similar results for the Neftegorskoe anomaly, although the selection of the volume was different for the two methods. A cylinder with a circle around the center of the aftershock area was used for the RTL-method, but a rectangle of dimensions maximizing the anomaly for the $Z$-map method. The estimated duration of 2.7 years and the estimate of the probability that this anomaly occurred by chance are the same.

The geographical extent of the anomaly (Table 5) is difficult to estimate because of the low seismicity rate. The dimensions of the strong anomaly, as mapped by RTL are about $100 \mathrm{~km}$, but the radius used for sampling was $400 \mathrm{~km}$. In the RTL-approach, we cannot use $R_{\max }=2 r_{o}<200 \mathrm{~km}$, because there would be too few earthquakes in the sample for statistical treatment. In the Z-map approach, the lta-function in the radius of $65 \mathrm{~km}$ around the Neftegorsk 1995 epicenter does not reach a highly significant level because the sample contains too few earthquakes (Fig. 2(a)). This figure can only serve to demonstrate that there occurred no earthquakes for 2.7 years in the epicentral area, but without Fig. 2(b), the anomaly would not be established as significant. The average extent of the rectangle (Fig. 1), which was used to select the sample for Fig. 2(b) is $400 \mathrm{~km}$. In both methods, the resulting maximum expression of the anomaly does not coincide with the epicenter (e.g. Fig. 4), but the volumes sampled from these most anomalous locations do include the source volumes. Neither do the two methods identify the same locations for the anomalous maximum.

There are two reasons for the differences between the methods in pinpointing the anomaly location. (1) Due to the sparseness of the data, only a couple of earthquakes in a given location at the time of quiescence can cause a shift of the center of the measured location of strongest anomaly. (2) The weighting of the results by the size of the earthquakes, which is only done in the RTL and not in the $Z$ map method, causes some differences in the estimated significance in most samples. Therefore, the maximum expressions of the anomaly are not observed at exactly the same locations.

For the Uglegorskoe earthquake, the estimated duration of the anomaly was 3.0 years and 2.5 years, using the RTL- and Z-method, respectively (Table 6). The anomaly dimensions were estimated as $165 \mathrm{~km}<R<400 \mathrm{~km}$, by the two methods. The estimates of the probability of chance-occurrence were again similar.

The two methods, based on different assumptions, different selection of sampling volumes, different algorithms and 
Table 6. Characteristics of Uglegorskoe Precursory Quiescence.

\begin{tabular}{|c|l|c|c|c|c|}
\hline Method & \multicolumn{1}{|c|}{ Dimensions } & $\begin{array}{c}\text { Uncertainty } \\
\text { Dimensions }\end{array}$ & $\begin{array}{c}\text { Duration } \\
\text { (years) }\end{array}$ & $\begin{array}{c}\text { Uncertainty } \\
\text { Duration }\end{array}$ & $\begin{array}{c}\text { Probability by } \\
\text { Chance }\end{array}$ \\
\hline RTL & $\begin{array}{l}R=200 \mathrm{~km} \text { around } \\
\text { epicenter }\end{array}$ & $100 \mathrm{~km}$ & 3.0 & 0.5 years & $2 \%$ \\
\hline $\mathrm{Z}$ & $\begin{array}{l}R=165 \mathrm{~km} \text { around } \\
\text { epicenter }\end{array}$ & $100 \mathrm{~km}$ & 2.5 & 0.5 years & $2 \%$ \\
\hline
\end{tabular}

different definitions of 'anomalies' arrived at very similar results (Tables 5 and 6). This strongly suggests that the observed anomalies are real and can be measured with considerable reliability. The uncertainty estimates we offer (Table 5 and 6) are based on the comparison of the results derived by the two methods. The uncertainty of duration is small (we suggest 0.5 years), but the uncertainty of location is fairly large (about $100 \mathrm{~km}$ ). Although the location difference is due to the use of different algorithms, the uncertainty is partly caused by low data density.

The properties of the two quiescence precursors in Sakhalin are similar to those of others documented by us. Their durations are similar to those observed elsewhere, but the dimensions are larger than in most cases. The large area of the anomaly may reflect the nature of the process leading to the phenomenon. Precursory quiescences, evaluated by various methods, have been reported by approximately 80 authors for different tectonic environments. In our own investigations, we have found quiescences in the following areas. (1) The compressive tectonic settings of the subduction and collision zones of Japan (Huang et al., 2001; Wyss et al., 1996, 1999a), Kamchatka (Saltikov and Kugaenko, 2000; Sobolev, 2001; Sobolev and Tyupkin, 1997, 1999), Aleutians (Kisslinger and Kindel, 1994; Wyss and Wiemer, 1999), and Armenia (Wyss and Martyrosian, 1998); (2) The strike-slip environments of California (Wiemer and Wyss, 1994; Wyss and Habermann, 1988a), Hawaii (Wyss and Fu, 1989) and Turkey (Huang et al., 2002; Wyss et al., 1995); and (3) The mostly normal faulting provinces of Italy (Giovambattista and Tyupkin, 1999; Wyss et al., 1997) and Utah (Arabasz and Wyss, 1996a). Given the widely differing tectonic conditions, and levels of stress, in these three zones of different types of faulting, one might expect strong differences in the preparation process for major ruptures. However, quantitatively documented precursory quiescences are found in all of these areas. They have in common that their precursor times are similar, but the ratios of the anomaly volume to the source volume varies by more than an order of magnitude. The fact that similar quiescence precursors are observed in areas of all tectonic styles strongly suggests that this type of precursor exists and should be investigated more fully.

Predictions of earthquakes based on seismic quiescence, which were essentially correct, are known to us for four cases. (1) The 1973 Nemuro Peninsula earthquake (M7.4) is regarded by Japanese seismologists as having been predicted successfully (Utsu, 1968, 1970, 1972). (2) The Oaxaca earthquake of 29 November 1978 (M7.8) appears to have been successfully predicted (Ohtake et al., 1977, 1981), although Whiteside and Habermann (1989) suggested the re- duction in reporting of earthquakes was artificially generated by changes in the process of recording earthquakes. (3) In 1985, the position, rupture length and occurrence time of an M4.7 earthquake along the San Andreas fault was correctly predicted (Wyss and Burford, 1985, 1987), although two false alarms were issued at the same time. (4) The M7.9 Andreanof Island earthquake was anticipated by Kisslinger and co-workers on the basis of quiescence (Kisslinger, 1986, 1988; Kisslinger et al., 1985). Although the interpretation of the quiescence as a precursor (before the Andreanof rupture occurred) was correct, the magnitude was underestimated and the six months time window was too short by two weeks. (5) On August 7, 1996, G. Sobolev and Yu. Tyupkin presented to the Expert Council on Earthquake Prediction of Russia's Ministry for Emergencies an RTL-anomaly that had started at the beginning of 1996 and was in a recovery stage. The center of this anomaly was located at $55^{\circ} \mathrm{N} / 162^{\circ} \mathrm{E}$ with dimensions of about $200 \times 200 \mathrm{~km}$. The interpretation was that this could be a precursor to an M7 earthquake that was expected to occur within 1 to 2 years. An Mw7.8 (Ms(ISC)7.4) earthquake occurred 16 months later, on December 5,1997 , at $54.8^{\circ} \mathrm{N} / 162.0^{\circ} \mathrm{E}$ (ISC).

False alarms have, however, also been issued. For example, we measured two episodes of clear quiescence in Japan and interpreted them as possible precursors (Wyss and Wiemer, 1997). Subsequently, the seismicity in these quiet volumes resumed at levels as before, without main shocks. This shows that transients can happen in the earth's crust that locally increase or decrease the seismicity rate strongly, but that do not lead immediately to main shocks. The M7.1 Landers earthquake of 1992 furnished an example in which seismicity was not only turned on for many years in some nearby volumes, but which also turned off the seismicity in other volumes adjacent to those in which the rate was increased by this redistributions of stress (Wyss et al., 1999b). It may be that similar redistribution of stress may also be achieved by creep transients, in which case quiescence may occur with or without a main shock following. At present, we do not know how to distinguish between precursory and other quiescences.

Cases of main shocks without precursory quiescence in areas where the data would have been sufficient to document precursors, had they existed, are also known. Unfortunately, these failures of the quiescence hypothesis are not well documented due to a lack of funding for systematic quiescence studies.

The absence of a clear-cut mechanical explanation of the quiescence phenomenon causes some seismologists to hesitate to accept the quiescence hypothesis. The early proposal that dilatancy may occur at a critical state before earthquake 
ruptures and cause hardening of source volumes (Scholz et al., 1973) has never been disproved, but it has gone out of vogue. In the two Sakhalin cases analysed here, it is difficult to imagine that dilatancy hardening could occur in volumes with dimensions of several hundred kilometers. The idea that precursory creep might cause a redistribution (with local reduction) of stress, and hence quiescence, is also old (e.g. Sobolev, 1995; Stuart, 1979). It is also not easy to accept the idea that strain softening might influence volumes at large distances. However, the evidence associated with some recent earthquakes clearly shows that the seismicity budget at large distances can be influenced strongly and over long periods (e.g. Bodin et al., 1994; Gomberg and Davis, 1996; Harris and Simpson, 1992; Hill et al., 1993, 1995; Stein et al., 1992; Wyss and Wiemer, 2000). Correlation with measurements of other parameters, such as crustal deformations, could be helpful in formulating an authoritative model for the phenomenon of precursory quiescence and for a better understanding of the initiation process of major crustal failure along faults better.

Although we are far from believing that earthquake prediction could soon become commonplace, it seems not unreasonable to work toward achieving some successes in favorable cases. Once Sakhalin has a new seismograph network, it would be possible to detect episodes of quiescence as demonstrated here. However, it would not be easy to predict the location or magnitude of a possible future main shock. The location cannot be pinpointed because the anomalous volumes were large (half of Sakhalin Island). To estimate the magnitude would also be difficult, because the features of the two anomalies reported here are very similar, although the magnitudes of the main shocks are not $\left(M_{w} 6.8\right.$ and $M_{w}$ 7.6). Nevertheless, we think it would be a mistake not to try and gather experience with forecasting earthquakes based on precursory seismic quiescence, a phenomenon that sometimes produces clear signals.

Acknowledgments. We thank Sakhalin Energy Investment Co. (SEIC) for supporting this research. SEIC is the operator of the Sakhalin II oil and gas venture, and is making significant upgrades to the island's infrastructure, including the seismic monitoring network. We also thank the Russian Academy of Sciences for supplying the data, and S. Wiemer for his software ZMAP and advice for plotting.

\section{References}

Arabasz, W. T. and M. Wyss, Quiescence in Utah, EOS, 102, 9999, 1996a. Arabasz, W. T. and M. Wyss, Significant precursory seismic quiescences in the extensional Wasatch front region Utah, EOS, 77, F455, 1996b.

Arefiev, S., E. Rogozhin, R. Tatevossian, L. Rivera, and A. Cisternas, The Neftegorsk (Sakhalin Island) 1995 earthquake: A rare interplate event, Geophys. J. Int., 143, 595-607, 2000.

Bodin, P., R. Bilham, J. Behr, J. Gomberg, and K. W. Hudnut, Slip triggered on southern California faults by the 1992 Jushoa Tree, Landers and Big Bear earthquakes, Bull. Seism. Soc. Am., 84, 806-816, 1994.

Chapman, M. E. and S. C. Solomon, North American-Eurasian plate boundary in northeast Asia, J. Geophys. Res., 81, 921-930, 1976.

Fournier, M., L. Jolivet, P. Huchon, K. F. Sergeyev, and L. S. Oscorbin, Neogene strike-slip faulting in Sakhalin and the Japan Sea opening, $J$. Geophys. Res., 99, 2701-2725, 1994.

Giovambattista, R. D. and Y. S. Tyupkin, The fine structure of the dynamics of seismicity before $m>=4.5$ earthquakes in the area of Reggio Emilia (Northern Italy), Annali di Geofisica, 42(5), 897-909, 1999.

Gomberg, J. and S. Davis, Stress/strain changes and triggered seismicity following the Mw7.3 Landers, California, earthquake, J. Geophys. Res.,
101, 751-764, 1996.

Habermann, R. E., Teleseismic detection in the Aleutian Island arc, J. Geophys. Res., 88, 5056-5064, 1983.

Habermann, R. E., Man-made changes of Seismicity rates, Bull. Seism. Soc. Am., 77, 141-159, 1987.

Harris, R. A. and R. W. Simpson, Changes in static stress on southern California faults after the 1992 Landers earthquake, Nature, 360, 251254, 1992.

Hill, D. P. et al., Seismicity remotely triggered by the magnitude 7.3 Landers, California, earthquake, Science, 260, 1617-1623, 1993.

Hill, D. P., M. J. S. Josnston, and J. O. Langbein, Response of Long Valley caldera to the $\mathrm{Mw}=7.3$ Landers, California, earthquake, J. Geophys. Res., 100, 12985-13005, 1995.

Huang, Q., G. Sobolev, and T. Nagao, Characteristics of seismic quiescence and activation patterns before the $M=7.2$ Kobe earthquake, January 17 , 1995, Tectonophysics, 337, 99-116, 2001.

Huang, Q., A. O. Oncel, and G. A. Sobolev, Precursory seismicity changes associated with the Mw=7.4 Izmit earthquake, August 17 1999, Geophys. J. Int., 151, 235-242, 2002.

Katsumata, K., M. Kasahara, M. Ichiyanagi, M. Kikuchi, R.-S. Sen, C.U. Kim, A. Ivaschenko, and R. Tatevossian, The May 27, $1995 \mathrm{Ms}=$ 7.6 Northern Sakhalin earthquake: An earthquake on an uncertain plate boundary, Bull. Seism. Soc. Am., 94, 117-130, 2004.

Kisslinger, C., Seismicity patterns in the Adak seismic zone and the shortterm outlook for a major earthquake, in Meeting of the National Earthquake Prediction Evaluation Council, pp. 119-134, Anchorage, Alaska, 1986.

Kisslinger, C., An experiment in earthquake prediction and the 7 May 1986 Andreanof Islands earthquake, Bull. Seism. Soc. Am., 78, 218-229, 1988.

Kisslinger, C., C. McDonald, and J. R. Bowman, Precursory time-space patterns of seismicity and their relation to fault processes in the central Aleutian Islands seismic zone, in IASPEI, 23d general assembly, pp. 32, Tokyo, Japan, 1985.

Kisslinger, K. and B. Kindel, A comparison of seismicity rates near Adak island, Alaska, September 1988 through May 1990 with rates before the 1982 to 1986 apparent quiescence, Bull. Seism. Soc. Am., 84, 1560-1570, 1994.

Matsu'ura, R. S., Precursory quiescence and recovery of aftershock activity before some large aftershocks, Bull. Earthq. Res. Inst., 61, 1-65, 1986.

Mogi, K., Some features of recent Seismic activity in and near Japan (2), Activity before and after great earthquakes, Bull. Earthq. Res. Inst., Univ. of Tokyo, 47, 395-417, 1969.

Molchan, G. M. and O. E. Dmitrieva, Identification of aftershocks: Review and new approaches, Computative Seismology, 24, 19-50, 1991 (in Russian).

Ohtake, M., T. Matumoto, and G. V. Latham, Seismicity gap near Oaxaca, Southern Mexico, as a probable precursor to a large earthquake, Pageoph, 115, 375-385, 1977.

Ohtake, M., T. Matumoto, and G. V. Latham, Evaluation of the forecast of the 1978 Oaxaca, Southern Mexico earthquake based on a precursory Seismic quiescence, in: Earthquake Prediction, Maurice Ewing Series, Amer. Geophys. Union, 4, 53-62, 1981.

Reasenberg, P. A., Second-order moment of Central California Seismicity, J. Geophys. Res., 90, 5479-5495, 1985.

Riznichenko, Y. V., Dimensions of the crustal earthquake focus and the seismic moment, Research in Earthquake Physics M., Nauka, 9-27, 1976 (in Russian).

Saltikov, V. A. and Y. A. Kugaenko, Seismic quiescence before two strong earthqaukes 1996 on Kamchatka, Volkanologiya i Seismologiya, 1, 57$65,2000$.

Scholz, C. H., L. R. Sykes, and Y. P. Aggarwal, Earthquake prediction: a physical basis, Science, 181, 803-810, 1973.

Seno, T., T. Sakurai, and S. Stein, Can the Okhotsk plate be discriminated from the North American plate?, J. Geophys. Res., 101, 11305-11315, 1996.

Shimamoto, T., M. Watanabe, Y. Suzuki, A. Kozhurin, M. Strel'tsov, and E. Rogozhin, Surface faults and damage associated with the 1995 Neftegorsk earthquake, J. Geol. Soc. Japan, 102, 894-907, 1996 (in Japanese).

Smirnov, V. B., Earthquake catalogs: Evaluation of data completeness, Volkanologiya i Seismologiya, 19, 433-446, 1998.

Sobolev, G., The examples of earthquake preparation in Kamchatka and Japan, Tectonophysics, 338, 269-279, 2001.

Sobolev, G. A., Fundamentals of Earthquake Prediction, 162 pp., Electromagnetic Research Center, Moscow, 1995.

Sobolev, G. A. and Y. S. Tyupkin, Low-seismicity precursors of large earthquakes in Kamchatka, Volcanology and Seismology, 18, 433-446, 1997. 
Sobolev, G. A. and Y. S. Tyupkin, Precursory phases, seismicity precursors, and earthquake prediction in Kamchatka, Volkanologiya i Seismologiya, 20, 615-627, 1999.

Soloviev, S. L. and O. N. Solovieva, The relation between the energy class and magnitude of Kuril earthquakes, Fizika Zemly, 2, 13-23, 1967 (in Russian).

Stein, R. S., G. C. P. King, and J. Lin, Change in failure stress on the San Andreas and surrounding faults caused by the $1992 M=7.4$ Landers earthquake, Science, 258, 1328-1332, 1992.

Stuart, W. D., Strain softening prior to two-dimensional strike slip earthquakes, J. Geophys. Res., 84, 1063-1070, 1979.

Utsu, T., Seismic activity in Hokkaido and its vicinity, Geophys. Bull. Hokkaido Univ., 20, 51-75, 1968 (in Japanese).

Utsu, T., Seismic activity and seismic observation in Hokkaido in recent years, Report of the Coodinating Committee for Earthquake Prediction, 2, 1-2, 1970 (in Japanese).

Utsu, T., Large earthquakes near Hokkaido and the expectancy of the occurrence of a large earthquakes off Nemuro, Report of the Coodinating Commitee for Earthquake Prediction, 7, 7-13, 1972 (in Japanese).

Whiteside, L. and R. E. Habermann, The seismic quiescence prior to the 1978 Oaxaca, Mexico, earthquake is not a precursor to that earthquake, abstract, in IASPEI, 25th General Assembly, pp. 339, Istanbul, Turkey, 1989.

Wiemer, S., A software package to analyze seismicity: ZMAP, Seismological Research Letters, 373-382, 2001.

Wiemer, S. and M. Wyss, Seismic quiescence before the Landers $(M=7.5)$ and Big Bear $(M=6.5) 1992$ earthquakes, Bull. Seism. Soc. Am., 84, 900-916, 1994.

Wyss, M., Evaluation of Proposed Earthquake Precursors, 94 pp., Washington, 1991.

Wyss, M., Nomination of precursory seismic quiescence as a significant precursor, Pure and Applied Geophysics, 149, 79-114, 1997a.

Wyss, M., Second round of evaluations of proposed earthquake precursors, Pure and Applied Geophysics, 149, 3-16, $1997 \mathrm{~b}$.

Wyss, M. and R. O. Burford, Current episodes of seismic quiescence along the San Andreas Fault between San Juan Bautista and Stone Canyon, California: Possible precursors to local moderate main shocks, U.S. Geol. Survey open-file report, 85-754, 367-426, 1985.

Wyss, M. and R. O. Burford, A predicted earthquake on the San Andreas fault, California, Nature, 329, 323-325, 1987.

Wyss, M. and Z. X. Fu, Precursory seismic quiescence before the January
1982 Hilea Hawaii earthquake, Bull. Seism. Soc. Am., 79, 756-773, 1989. Wyss, M. and R. E. Habermann, Precursory quiescence before the August 1982 Stone Canyon, San Andreas fault, earthquakes, Pure and Applied Geophysics, 126, 333-356, 1988a.

Wyss, M. and R. E. Habermann, Precursory Seismic quiescence, Pure and Applied Geophysics, 126, 319-332, 1988b.

Wyss, M. and A. H. Martyrosian, Seismic quiescence before the M7, 1988, Spitak earthquake, Armenia, Geophysical Journal International, 124, 329-340, 1998.

Wyss, M. and S. Wiemer, Two current seismic quiescences within $40 \mathrm{~km}$ of Tokyo, Geophysical Journal International, 128, 459-473, 1997.

Wyss, M. and S. Wiemer, How can one test the seismic gap hypothesis? The Case of repeated ruptures in the Aleutians., Pure and Applied Geophysics, 155, 259-278, 1999.

Wyss, M. and S. Wiemer, Change in the probability for earthquakes in Southern California due to the Landers magnitude 7.3 earthquake, Science, 290, 1334-1338, 2000.

Wyss, M., M. Westerhaus, H. Berkhemer, and R. Ates, Precursory seismic quiescence in the Mudurnu Valley, North Anatolian fault zone, Turkey, Geophysical Journal International, 123, 117-124, 1995.

Wyss, M., K. Shimazaki, and T. Urabe, Quantitative mapping of a precursory quiescence to the Izu-Oshima 1990 (M6.5) earthquake, Japan, Geophysical Journal International, 127, 735-743, 1996.

Wyss, M., R. Console, and M. Murru, Seismicity rate change before the Irpinia $(M=6.9) 1980$ earthquake, Bull. Seism. Soc. Am., 87, 318-326, 1997.

Wyss, M., A. Hasegawa, S. Wiemer, and N. Umino, Quantitative mapping of precursory seismic quiescence before the 1989, M7.1, off-Sanriku earthquake, Japan, Annali di Geophysica, 42, 851-869, 1999a.

Wyss, M., S. Hreinsdottir, and D. A. Marriott, Southern extent of the October 1999 M7.1 Hector Mine earthquake limited by Coulomb stress changes due to the M7.3 Landers earthquake of 1992, EOS, abstract, 1999 b (in press).

Zanyukov, V. N., The central Sakhalin fault and its role in the tectonic evolution of the island, Dokl. Akad. Nauk SSSR, Engl. Transl., 196, 85, 1971.

M. Wyss (e-mail: wapmerr@maxwyss.com), G. Sobolev, and J. D. Clippard 